\title{
Topical Application of Mitomycin C in Functional Endoscopic Sinus Surgery
}

\author{
Roby T Koshy ${ }^{1}$, Surianarayanan Gopalakrishnan², Padmanabhan Karthikeyan ${ }^{3}$
}

\begin{abstract}
Background: Functional endoscopic sinus surgery (FESS) is the surgical management of choice for chronic rhinosinusitis (CRS). However, the results do not give optimal results due to the development of synechiae, which results in recurrence of the sinusitis. Intraoperative use of mitomycin C (MMC) reduces the incidence of postoperative development of synechiae in patients undergoing FESS. This review attempts to provide a brief overview for application of MMC during FESS.

Materials and methods: In this article, we reviewed various randomized, clinical, and experimental trials conducted between 1990 and 2015 and which were published in various Indian and American journals. Literature search was conducted after using the key words endoscopic sinus surgery (ESS), triamcinolone acetonide, and MMC from Pubmed, Cochrane, Proquest, and Google Scholar.

Conclusion: The topical use of MMC and triamcinolone acetonide was comparable in reducing the formation of synechiae and crusts in the postoperative period and thereby improving the outcome.

Keywords: Endoscopic sinus surgery, Mitomycin C, Triamcinolone acetonide.

Annals of SBV (2020): 10.5005/jp-journals-10085-8106
\end{abstract}

\section{INTRODUCTION}

Chronic rhinosinusitis (CRS) is the edema and inflammation of mucosa of nose and paranasal sinuses, with or without sinonasal polyp formation. Per the standard definition, symptoms should last for a minimum of 8 weeks to make a diagnosis of CRS. Major symptoms are rhinitis, obstruction of the nose, facial pain, hyposmia, and postnasal discharge. ${ }^{1}$

Allergy is found to be one of the most important causative factors seen associated with CRS. Allergy-induced inflammatory mucosal edema causes obstruction of sinus ostia, which further causes stagnation of secretions. Bacterial infection in CRS is secondary to the reduction in ventilation of sinuses and obstructed drainage of secretions.

Medical line of management of CRS focuses on relieving the edema of the mucosa, which thereby reduces the obstruction of ostia and reestablishes the sinus ventilation and drainage.

Topical steroids, antibiotics, and mucolytics are used in the treatment of CRS. Surgery is indicated after 3-4 weeks when medical treatment fails. ${ }^{2}$

Introduction of ESS was a turning point in the surgical treatment of CRS. Clearance of the pathology and preservation of the normal functions of the mucosa like mucociliary clearance led to the development of functional endoscopic sinus surgery (FESS). ${ }^{3}$

The two major causes of failure of ESS is postoperative crust formation and synechiae. Careful postoperative care which includes frequent douching of nasal cavity or usage of nasal decongestant/ topical spray can prevent crusting and adhesions. Perioperative use of mitomycin $\mathrm{C}(\mathrm{MMC})$ reduces the rate of formation of synechiae in patients undergoing FESS. ${ }^{4}$

\section{Materials and Methods}

In this article, we reviewed various randomized, clinical, and experimental trials conducted between 1997 and 2016 and which were published in various Indian and American journals.
${ }^{1-3}$ Department of ENT, Mahatma Gandhi Medical College and Research Institute, SBV Deemed to be University, Puducherry, India

Corresponding Author: Padmanabhan Karthikeyan, Department of ENT, Mahatma Gandhi Medical College and Research Institute, SBV Deemed to be University, Puducherry, India, Phone: +91 9443381302, e-mail: karthikent73@gmail.com

How to cite this article: Koshy RT, Gopalakrishnan S, Karthikeyan P. Topical Application of Mitomycin C in Functional Endoscopic Sinus Surgery. Ann SBV 2020;8(1):19-22.

Source of support: Nil

Conflict of interest: None

Literature search was conducted after using the key words FESS, CRS, MMC, and triamcinolone acetonide in combination or in isolation from Pubmed, Cochrane, Proquest, and Google Scholar.

\section{Chronic Rhinosinusitis}

Chronic rhinosinusitis is an inflammatory disease of the nose and paranasal sinus, with many etiological factors. It occurs in isolation but also in combination with systemic disorders such as chronic bronchial asthma, allergic perennial rhinitis, inflammatory bowel disease, and cystic fibrosis. ${ }^{5}$

Thus, CRS is a common disease for which many patients undergo surgical treatment annually. ${ }^{6}$

\section{Endoscopic Sinus Surgery}

Kennedy, in 1985, first mentioned ESS in the North American scientific literature. It is considered as the most potent way of reestablishing mucociliary clearance and ventilation of the sinuses, by means of removing unhealthy mucosa and bone from the nasal cavity. ${ }^{7}$

The advantages of this method include good visualization, with less trauma and bleeding. In 1994, Maran found that "Endoscopic nasal surgery has become a major advance in the specialty of 
otolaryngology since the introduction of the operating microscope and middle ear surgery." Since then, there have been various studies demonstrating the various benefits of ESS. These studies have proved improvement in olfaction, general health, and quality of life. More recent studies have compared the two major modalities of treatment of CRS, namely, ESS in combination with corticosteroids and corticosteroids alone. The benefit of ESS in the management of CRS is largely accepted. ${ }^{8}$

Complications of ESS are rare with experienced hands. However, the major complications that are commonly encountered are orbital injuries, such as hematoma or extraocular muscle injuries, and injuries to skull base. One of the potential advantages of preoperative corticosteroids would be to reduce intraoperative edema and polyp load as well as reduce the degree of inflammation and blood loss, thereby improving visualization intraoperatively and thus helping in the surgery and proper disease clearance. ${ }^{9}$

\section{Perioperative Management for ESS}

A lot of variability in data are observed regarding perioperative medical therapy in patients undergoing ESS. Although many surgeons believe that routine postoperative care after endoscopic debridement optimizes surgical outcomes; however, the evidences are conflicting.

A significant amount of literature exists investigating various aspects of postoperative management. These studies provided conflicting results. ${ }^{10}$

\section{Mitomycin C}

It is an antibiotic agent isolated from Streptococcus caespitosus by Wakaki and associates in 1958. The use of MMC has been reduced since it has been replaced by more effective and nontoxic drugs. Mitomycin has a quinone group, an azauridine group, and a mitotane ring in its structure, which involves in the alkylation reaction with DNA. ${ }^{11}$

\section{Mechanism of Action}

After chemical reduction of the quinone and loss of the methoxy group, mitomycin becomes an alkylating agent with different functions. The drug inhibits the synthesis of DNA. In addition, mitomycin breaks the chromosome and single-stranded DNA. Mitomycin is also used as a potent radiosensitizer and is teratogenic. $^{12}$

\section{Therapeutic Uses}

Mitomycin is administered by parenteral infusion; extravasations may cause severe local injury. The drug is given as a bolus injection every 6 weeks. Dosage is modified based on hematological recovery. Mitomycin $C$ may also be used by direct instillation into the bladder to treat superficial carcinomas. ${ }^{13}$

\section{Use of MMC in Intranasal Surgery}

The use of MMC has been increasingly popular in dacrocystorhinostomy (DCR), and there are very few studies looking into all the variables like, dosage, route of delivery/and application, and the time of exposure; that play variable roles in the final outcome of the surgery. The intraoperative application with different doses of MMC in external DCR in 50 eyes was studied in a randomized control study by You and Fang. One group got $0.2 \mathrm{mg} / \mathrm{mL}$ of MMC and the other group got $0.5 \mathrm{mg} / \mathrm{mL}$, both for a duration of
5 minutes. ${ }^{14}$ The two groups were compared with a control group without MMC. The patency rate and osteotomy size differences of the patients treated with MMC and that of control group were found to be statistically significant. However, there was no significant statistical difference between the two groups in which MMC was used. Gonzalvo Ibanez et al. ${ }^{15}$ studied the effects of intraoperative MMC on the clinical evolution and osteotomy size following an external DCR with helical computed tomography we. With respect to MMC, in a comparative study conducted by Chung et al. on 55 patients with bilateral ESS, $1 \mathrm{~mL}$ of $0.04 \mathrm{mg} / \mathrm{mL}$ MMC was applied to the infundibulum of one side and saline-soaked pledget to the other side; and it was observed that the rate of adhesions was $3.6 \%$ on the MMC side, whereas it was 14.5 on the side with saline, a result that almost achieved statistical significance. ${ }^{16}$

To understand the action of topical application of MMC as an adjunct to endonasal DCR, Rathore et al. placed a nasal pack for 48 hours which was soaked in $1 \mathrm{~mL}$ of $0.05 \%$ ( $2 \mathrm{mg}$ in $5 \mathrm{~mL}$ of distilled water) MMC after DCR. They observed that there were no side effects on keeping these packs in the postoperative period. Improvement in symptoms like watering of eyes, nasal obstruction was noted in all patients who had nasal packing with MMC. Postoperatively, the nasal cavity which received MMC pack was remarkably normal in comparison to the control group who had saline nasal pack, where synechiae was seen in $65.2 \%$ of the patients during follow-up. ${ }^{17}$

Deka et al. ${ }^{18}$ used three groups to study the effects of duration of application and concentration of MMC: control group, operated without MMC; experimental group II, used MMC at a concentration of $0.05 \mathrm{mg} / \mathrm{mL}$ for 2 minutes; and experimental group III, with MMC applied at a concentration of $0.4 \mathrm{mg} / \mathrm{mL}$ for 2 minutes. They concluded that group III had significantly bigger ostium size in comparison to groups I and II.

Yildirim et al. ${ }^{19}$ in a study which used MMC as an adjunct in external DCRs noted that though the success rates of the MMC group were higher than the control group, the differences were not statistically significant. Prasannaraj et al., ${ }^{20}$ in their comparative study on the role of MMC in endoscopic DCR success rate, randomized 38 patients into an MMC group $(0.2 \mathrm{mg} / \mathrm{dL})$ and a control group. They reported a success rate of $82.3 \%$ with MMC, and $85.7 \%$ without MMC, which had no statistical significance. Granulations and adhesions occurred in a similar number of patients in both groups, and the authors opine that these complications did not tell anything about the rate of success in either group.

Feng et al. ${ }^{21}$ in their meta-analysis of primary external DCR with and without MMC included nine randomized controlled trials reporting on a total of 562 DCRs including patients in the age range of 30-57 years. They mentioned that there were significantly greater success rates in the MMC group in comparison with the control group. The meta-analysis also showed the favorable outcomes of intraoperative MMC application as a safe adjuvant in helping to maintain the patency of the ostium. Chang et al. in their recently published analysis of endoscopic DCRs to compare the clinical results with and without $M M C$ concluded that in addition to being safe, MMC reduces the rate of closure of osteotomy and increases the success rate after both primary and revision DCR. ${ }^{22}$

\section{Dosage and Duration}

It is evident that various studies have used different concentrations that there is no clear-cut evidence regarding the dose to be used. 
It is again not clear how investigators arrived at a concentration before applying it to practice. Ali et al. ${ }^{23}$ studied the action of different concentrations of MMC and treatment durations on cellular proliferation and viability of the fibroblasts. Cell viability, cellular proliferation, and the actin cytoskeletons of fibroblasts were studied using nasal mucosa harvested from patients undergoing a DCR. The findings of this study were that the doubling time of cultured nasal mucosal fibroblasts was found to be approximately 24 hours. Mitomycin $C$ at $0.4 \mathrm{mg} / \mathrm{mL}$ beyond 5 minutes and 0.5 $\mathrm{mg} / \mathrm{mL}$ concentration at all time points were lethal and caused extensive cell death when compared with controls. The minimum effective arbitrary concentration to be used was $0.2 \mathrm{mg} / \mathrm{mL}$ for a duration of 3 minutes as it reduces the cellular proliferation of the fibroblasts most probably due to arrest in cell cycle, without causing much cell death. ${ }^{22}$

Ingrams et al. showed a reduction in fibrosis allowing epithelialization to occur, thus decreasing the morbidity in FESS. Work done by Chung et al., Gupta and Motwani, and Konstantinidis et al. showed a reduction in the incidence of synechiae with topical MMC. ${ }^{23,24}$ Gupta and Motwani also reported an improvement in nasal obstruction in their patients who were treated with topical MMC.

Ingram et al. reported decreased adhesions after using sponges dipped with MMC placed at the ostium of the middle meatal antrostomy for 5 minutes. ${ }^{25}$ In a clinical study by Chung et al., adhesions were identified in 16 of 55 postoperative ESS patients, with significant adhesion formation on the untreated side as compared to the mitomycin side. ${ }^{16}$ Gupta et al. applied MMC topically following ESS and reported that it was helpful in improving symptoms such as nasal obstruction and hyposmia as well as decreasing adhesion rate and middle meatal antrostomy closure rate. ${ }^{26}$ Carifi reported that $2 \%$ of the patients complained of slight burning sensation following topical application of MMC; however, none of our patients complained of any burning sensation. ${ }^{27}$

In the study done by Karkos et al., the concentration of MMC ranged from low $(0.3 \mathrm{ng} / \mathrm{dL})$ to maximum concentration $(0.6 \mathrm{ng} / \mathrm{dL})$ and was applied with the help of different materials such as ribbon gauze, Merocel, and cotton pledget, ${ }^{28}$ whereas in our study we used a fixed concentration of MMC $(0.5 \mathrm{ng} / \mathrm{dL})$ throughout the study, and it was applied for a fixed duration of 2 minutes using gel foam only. This method, concentration, and duration of application were kept constant throughout the study.

The role of MMC in postoperative adhesions after ESS was studied by Thilak Raj et al., Gupta et al., and Anand et al., all of which used a smaller sample size of 30 each. However, in this study, we used a bigger sample size of 40 .

Anand et al. studied the effects of MMC in synechiae formation in FESS. In a 15-month follow-up period involving 29 patients, 12 episodes of synechiae formation were observed. Of the 12 episodes, 7 (24.13\%) occurred on the MMC side application, while 5 (17.24\%) occurred on the control side. They concluded that MMC was not effective in decreasing the incidence of synechiae formation. ${ }^{29}$

\section{Conclusion}

The results of FESS are often suboptimal due to the presence of postoperative synechiae. The use of topical MMC and triamcinolone acetonide was comparable in the reduction of incidence of synechiae and crusting in the postoperative period, thereby improving the results of the surgery.
No consensus on the concentration of drug, duration of application, and mode of drug delivery was observed. None of the studies mentions about the adverse effects. Since different studies have used different doses and duration of MMC application, future studies can be recommended to find the most efficient mode and type of drug delivery; and more clarity should be obtained on the minimum effective duration of drug application.

\section{References}

1. Benninger MS, Ferguson BJ, Hadley JA. Adult chronic rhinosinusitis: definitions, diagnosis, epidemiology and pathophysiology. Otolaryngol Head Neck Surg 2003;129(3 Suppl):S1-S32. DOI: 10.1053/ hn.2003.v128.amhn0312811.

2. Benninger MS. Nasal endoscopy: its role in office diagnosis. Am J Rhinol 1997;11(2):177-180. DOI: 10.2500/105065897782537205.

3. Zinreich S. Paranasal sinus imaging. Otolaryngol Head Neck Surg 1990;103(5_suppl):863. DOI: 10.1177/01945998901030S505.

4. Meltzer EO, Hamilos DL, Hadley JA. Rhinosinusitis: establishing definitions for clinical research and patient care. Otolaryngol Head Neck Surg 2004;131(6 Suppl):S1-S62. DOI: 10.1016/j. otohns.2004.09.067.

5. Gosepath J, Mann WJ. Current concepts in therapy of chronic rhinosinusitis and nasal polyposis. ORL J Otorhinolaryngol Relat Spec 2005;67(3):125-136. DOI: 10.1159/000086075.

6. Rowe-Jones JM, Medcalf M, Durham SR, Richards DH, Mackay IS. Functional endoscopic sinus surgery: 5 year follow up and results of a prospective, randomised, stratified, double-blind, placebo controlled study of postoperative fluticasone propionate aqueous nasal spray. Rhinology 2005;43(1):2-10. . Neurol. 2012;3:1-9.

7. Sackett DL, Richardson WS, Rosenberg WM, Hayes RB. Evidence-based Medicine: How to Practice and Teach EBM. 2nd ed., London: Churchill Livingstone; 2000.

8. May M, Levine HL, Mester SJ, et al. Endoscopic sinus surgery. In endoscopic sinus surgery. Levine HL, May M, ch. 5, New York: Thieme Medical Publishers; 1993.

9. Marks SC. Endoscopic sinus surgery. In: Marks SC. Textbook on nasal and sinus surgery. W. B. Saunders Company; 2000. pp 119, $125-26,140-141$.

10. Kennedy DW, Zinreich SJ, Rosenbaum AE, Johns ME. Functional endoscopic sinus surgery. Theory and diagnostic evaluation. Arch Otolaryngol 1985;111(9):576-582. DOI: 10.1001/ archotol.1985.00800110054002.

11. Khaw PT, Doyle JW, Sherwood MB, Grierson I, Schultz G, McGorray S. Prolonged localized tissue effects from 5-minute exposures to fluorouracil and mitomycin C. Arch Ophthalmol 1993;111(2):263-267. DOI: 10.1001/archopht.1993.01090020117035.

12. Kao SCS, Liao CL, Tseng JHS. Dacryocystorhinostomy with intraoperative mitomycin C. Ophthalmology 1996;104(1):86-91. DOI: 10.1016/S0161-6420(97)30357-1.

13. Eliashar R, Eliachar I, Esclamado R, Gramlich T, Strome M. Can topical Mitomycin prevent laryngotracheal stenosis? Laryngoscope 1999;109(10):1594-1600. DOI: 10.1097/00005537-19991000000009.

14. You YA, Fang CT. Intraoperative mitomycin C in dacryocystorhinostomy. Ophthal Plast Reconstr Surg 2001;17(2):115-119. DOI: 10.1097/00002341200103000-00007.

15. Gonzalvo Ibanez FJ, Fuertes Fernandez I, Fernandez Tirado FJ, Hernandez Delgado G, Rabinal Arbues F, Honrubia Lopez FM. External dacryocystorhinostomy with mitomycin C. Clinical and anatomical evaluation with helical computed tomography. Arch Soc Esp Oftalmol 2000;75(9):611-617.

16. Rathore PK, Kumari Sodhi P, Pandey RM. Topical mitomycin C as a postoperative adjunct to endonasal dacryocystorhinostomy in patients with anatomical endonasal variants. Orbit 2009;28(5): 297-302. DOI: 10.3109/01676830902856328. 
17. Chung JH, Cosenza MJ, Rahaber R, Metson RB. Mitomycin C for the prevention of adhesion formation after endoscopic sinus surgery: a randomized, controlled study. Otolaryngol Head Neck Surg 2002;126(5):468-474. DOI: 10.1067/mhn.2002.124705.

18. Deka A, Bhattacharjee $\mathrm{K}$, Bhuyan SK, Barua CK, Bhattacharjee $\mathrm{H}$, Khaund G. Effect of mitomycin Con ostium in dacryocystorhinostomy. Clin Experiment Ophthalmol 2006;34(6):557-561. DOI: 10.1111/j.14429071.2006.01265.x.

19. Yildirim C, Yaylali V, Esme A, Ozden S. Long term results of adjunctive use of mitomycin $C$ in external dacryocystorhinostomy. Int Ophthalmol 2007;27(1):31-35. DOI: 10.1007/s10792-007-9057-6.

20. Prasannaraj T, Kumar BY, Narasimhan I, Shivaprakash KV. Significance of adjunctive mitomycin C in endoscopic dacryocystorhinostomy. Am J Otolaryngol 2012;33(1):47-50. DOI: 10.1016/j.amjoto.2011.01.001.

21. Feng YF, Yu JG, Shi JL, Huang JH, Sun YL, Zhao YE. A meta-analysis of primary external dacryocystorhinostomy with and without mitomycin C. Ophthalmic Epidemiol 2012;19(6):364-370. DOI: 10.3109/09286586.2012.733792.

22. Cheng SM, Feng YF, Xu L, Li Y, Huang JH. Efficacy of mitomycin C in endoscopic dacryocystorhinostomy; a systematic review and meta-analysis. PLoS ONE 2013;8(5):e62737. DOI: 10.1371/journal. pone.0062737.

23. Ali MJ, Baig F, Lakshman M, Naik MN. Electron microscopic features of nasal mucosa treated with topical and circumostial injection of mitomycin C: implications in dacrycystorhinostomy. Ophthal Plast Reconstr Surg 2015;31(2):103-107. DOI: 10.1097/ IOP.0000000000000205.

24. Ali KJ, Mariappan I, Maddileti S, Ali MH, Naik MN. Mitomycin C in dacryocystorhinostomy: the search for the right concentration and duration - a fundamental study on human nasal mucosa fibroblasts. Ophthal Plats Reconstr Surg 2013;29(6):469-474. DOI: 10.1097/ IOP.0b013e3182a23086.

25. Ingram DR, Volk MS, Biesman BS, Pankratov MM, Shapshay SM. Sinus surgery: does mitomycin $C$ reduce stenosis? Laryngoscope 1998;108(6):883-886. DOI: 10.1097/00005537-199806000-00017.

26. Gupta M, Motwani G. Role of mitomycin C in reducing adhesion formation following endoscopic sinus surgery. J Laryngol Otol 2006;120(11):921-923. DOI: 10.1017/S0022215106001952.

27. Carifi M. Adjuvant mitomycin $C$ in functional endoscopic sinus surgery. Eur Arch Otorhinolaryngol 2013;270(3):1173-1174. DOI: 10.1007/s00405-012-2164-7.

28. Karkos PD, Leong SC, Sastry A, Assimakopoulos AD, Swift AC. Evidence-based applications of mitomycin $C$ in the nose. Am J Otolaryngol 2011;32(5):422-425. DOI: 10.1016/j.amjoto.2010.07.022.

29. Anand VK, Tabaee A, Kacker A, Newman JG, Huang C. The role of mitomycin $C$ in preventing synechiae and stenosis after endoscopic sinus surgery. Am J Rhinol 2004;18(5):311-314. DOI: 10.1177/194589240401800509. 